\title{
ATUAÇÃO MUNICIPAL NA MITIGAÇÃO DE IMPACTOS AMBIENTAIS
}

\author{
Ricardo Azevedo Mamédio de Sousa \\ Possui graduação em Direito (2017) e em Engenharia Ambiental (2014) pela Universidade \\ Federal do Tocantins. Atualmente é engenheiro ambiental da Fundação de Meio Ambiente de \\ Palmas, com lotação na gerência de licenciamento ambiental. \\ Email: ricardomamedio88@gmail.com \\ Renata Rodrigues de Castro Rocha \\ Doutora (2012) e mestre em Ciência Florestal (2009), graduada em Direito pela Universidade \\ Federal de Viçosa - UFV. Concluiu pós-graduação em Direito Tributário pela Universidade \\ Cândido Mendes, RJ, em 2006. É professora adjunta da \\ Universidade Federal do Tocantins (UFT). \\ Email: renatarocha@uft.edu.br
}

\section{RESUMO}

Opresente trabalhobuscouverificararegulação da exigência de compensação ambiental para empreendimentos que, embora não se equiparem aos exemplificados no art. $2^{\circ}$ da Resolução Conama $n^{\circ} 001$, de 23 de janeiro de 1986, produzem impactos com consequências sensíveis à qualidade do meio ambiente natural, situando-se em posição intermediária na escala de atividades potencialmente prejudiciais às condições ecológicas da sua área de influência. Para tanto, através de pesquisa bibliográfica e análise da legislação e doutrina pertinentes ao objeto de pesquisa, analisou-se o conceito e a natureza jurídica do instituto da compensação ambiental, bem como a posição ocupada pelos municípios na distribuição de competências material e legislativa nessa seara. Concluiu-se pela viabilidade da instituição de compensação ambiental municipal por impactos de média magnitude, assim como pela possibilidade de sedestinar os recursos arrecadados para a restauração das funções ecológicas essenciais à conservação da natureza e à sadia qualidade de vida da população, e não exclusivamente para a criação e manutenção de unidades de conservação.

Palavras-chave: Compensação Ambiental. Impacto Ambiental. Competência Material. 


\title{
MUNICIPAL ACTION IN THE MITIGATION OF ENVIRONMENTAL IMPACTS
}

\begin{abstract}
The present work sought to verify the regulation of the requirement of environmental compensation for projects that, although not similar to those exemplified in art. 2 of Conama Resolution $n^{\circ}$ 001, of January 23, 1986, produce impacts with consequences sensitive to the quality of the natural environment, being placed in an intermediate position in the scale of activities potentially harmful to the ecological conditions of its area of influence. To do so, through bibliographic research and analysis of legislation and doctrine relevant to the object of research, the concept and legal nature of the environmental compensation institute was analyzed, as well as the position occupied by municipalities in the distribution of material and legislative competences in this area. The conclusion of the feasibility of the municipal environmental compensation institution due to impacts of medium magnitude, as well as the possibility of earmarking the resources collected for the restoration of the ecological functions essential to the conservation of nature and the healthy quality of life of the population, and not exclusively for the creation and maintenance of conservation units.
\end{abstract}

Keywords: Environmental Compensation. Environmental impact. Material Competence. 


\section{INTRODUÇÃO}

A Constituição Federal de 1988, por meio de seu art. 225, conferiu a todos o direito ao meio ambiente ecologicamente equilibrado, bem de uso comum do povo e essencial à sadia qualidade de vida, impondo ao Poder Público e à coletividade o dever de defendê-lo e preservá-lo para as presentes e futuras gerações. Além disso instituiu, em seu art. 170, a proteção do meio ambiente como princípio da ordem econômica.

Como forma de efetivar a tutela do meio ambiente, criou incumbências ao Poder Público, que passou a ter, dentre outros deveres, o de preservar e restaurar os processos ecológicos essenciais; definir espaços territoriais e seus componentes a serem especialmente protegidos; exigir para instalação de obra ou atividade potencialmente causadora de significativa degradação do meio ambiente, estudo prévio de impacto ambiental; e proteger a fauna e a flora, vedadas as práticas que coloquem em risco sua função ecológica, provoquem a extinção de espécies ou submetam os animais a crueldade.

Dado o status ocupado pelo meio ambiente na ordem constitucional vigente, o objetivo precípuo que informa toda a legislação ambiental é a prevenção e a precaução. Quando este objetivo não se realiza e danos ambientais são causados, nosso sistema legal e jurídico está orientado a perseguir a restauração do bem ambiental. Verificada a impossibilidade da recuperação, resta, ainda, a possibilidade de se realizar uma compensação ambiental, consistente na substituição de um bem ambiental danificado por outro que lhe equivalha na prestação de serviços ecológicos.

No ordenamento jurídico brasileiro estão previstas, como espécies de compensação ambiental, devidas em razão de danos provocados ao meio ambiente: (a) compensação por dano ambiental irreversível; (b) compensação para supressão de Área de Preservação Permanente; (c) compensação de Reserva Legal; (d) compensação para supressão de Mata Atlântica; e (e)compensação para implantação de empreendimentos causadores de significativo impacto ambiental.

A compensação para implantação de empreendimentos causadores de significativo impacto ambiental está prevista no art. 36 da Lei $\mathrm{n}^{0} 9.985 / 2000$, e consiste em obrigação devida pelo empreendedor nos casos de licenciamento ambiental de empreendimentos que impactem o meio ambiente de modo significativo, assim considerado pelo órgão ambiental competente, com fundamento em estudo de impacto ambiental e 
respectivo relatório - EIA/RIMA, e cujos recursos são destinados a apoiar a implantação e manutenção de unidade de conservação, preferencialmente do Grupo de Proteção Integral.

A opção do legislador federal teve como escopo financiar o Sistema Nacional de Unidades de Conservação (Snuc), de forma a dar concretude à disposição constitucional segundo a qual cabe ao Poder Público "definir, em todas as unidades da Federação, espaços territoriais e seus componentes a serem especialmente protegidos" (CF/1988, art. 225, $\S 1^{\circ}$, III).

Contudo, não obstante o relevante papel prestado pela compensação do Snuc na preservação de extensas áreas, entende-se que ao desconsiderar outras formas de se buscar a manutenção do equilíbrio ecológico, o legislador federal acabou por privilegiar investimentos que muitas vezes não geram os benefícios ambientais que melhor representam as necessidades de uma localidade. Ou seja, limitar a aplicação de recursos da compensação ambiental à criação e manutenção de unidades de conservação de proteção integral é ignorar a importância de todas as outras medidas necessárias à efetivação das políticas ambientais de nível local.

Diante dos problemas apontados, buscou-se, com auxílio de pesquisa bibliográfica e análise da legislação e doutrina pertinentes ao objeto de pesquisa, debater o conceito, as espécies, a natureza jurídica e a constitucionalidade do instituto da compensação ambiental, bem como a posição ocupada pelos municípios na distribuição de competências material e legislativa nessa seara.

$\mathrm{Na}$ sequência, propôs-se com o presente estudo, a partir da compreensão da mencionada compensação ambiental da Lei $n^{\circ}$ 9.985/2000, a instituição, pelos municípios, de uma espécie de compensação ambiental mais restritiva, devida em razão de impactos ambientais irreversíveis de média magnitude, assim considerados pelo órgão ambiental com base em estudo ambiental, não necessariamente EIA-RIMA.

Por fim, avaliou-se a possibilidade de se destinar os recursos financeiros arrecadados em medidas que visem a manutenção do equilíbrio ecológico de forma ampla, e não exclusivamente pela implantação e manutenção de unidades de conservação. 


\section{COMPENSAÇÃO AMBIENTAL NA LEGISLAÇÃO BRASILEIRA}

Conforme notado por Bechara (2007, p. 158), "o termo compensação é utilizado em várias situações e, em cada uma delas, para designar institutos distintos, embora, no mais das vezes, próximos". Para a referida autora esta proximidade se deve ao fato de que a compensação, no Direito Ambiental,

[...] tem por finalidade primordial fazer com que uma atividade degradadora ou poluidora que afete negativamente o equilíbrio ambiental por agredir algum de seus elementos corpóreos ou incorpóreos, ofereça uma contribuição para afetá-lo positivamente, melhorando a situação de outros elementos corpóreos e incorpóreos que não os afetados. (2007, p.158).

Tal delimitação semântica concilia-se com a apresentada por Milaré e Artigas(2006, [s.p]), para quem compensar significa "suprir, com um peso ou valor equivalente, algo que se danificou, tirou ou subtraiu, levando-se em conta o significado ecossistêmico, científico e social do bem lesado, e não apenas o simples valor material, econômico ou financeiro".

A opção do legislador, evidenciada nos arts. $4 .^{\circ}, \mathrm{VII}$, e $14, \S 1 .^{\circ}$ da Lei $.^{\circ}{ }^{\circ} 6.938 / 1981$ e art. $225, \S 3 .^{\circ}$, da $\mathrm{CF} / 1988$, indica que, em primeiro plano, deve-se tentar a restauração do bem ambiental e, quando esta for inviável, partir-se para a indenização por sucedâneo ou compensação (LEITE e AYALA, 2015).

Trata-se, portanto, em sentido amplo, da obrigação de substituir um bem lesado por outro de valor equivalente, imposta ao causador do dano nas hipóteses de irreversibilidade da lesão. Isto é: a compensação (ou substituição do bem) apenas pode ocorrer quando se concluir pela impossibilidade da restauração do bem prejudicado.

$\mathrm{Na}$ formulação de Leite e Ayala (2015), enquanto a restauração visa à reintegração, à recomposição ou à recuperação in situ dos bens ambientais lesados (retorno ao status quo ante), a compensação objetiva a substituição dos bens ambientais afetados por outros funcionalmente equivalentes.

Assim, à guisa de conclusão, Mauricio Mota observa que 
a disciplina da compensação ambiental, mesmo sem estar precisamente delineada teoricamente, vem se afigurando doutrinariamente como uma retribuição adequada pelo exercício concentrado e particular de um direito difuso ao meio ambiente ecologicamente equilibrado (art. 225 da CF/88) (MOTA, 2015,p.777).

Para Mota, o instituto da compensação ambiental, em que pese o seu estágio de desenvolvimento teórico, funda-se no reconhecimento da função socioambiental da propriedade, que harmoniza-se com a noção de "usuário pagador".

\subsection{Da natureza jurídica do instituto}

Há relevante divergência doutrinária acerca da natureza jurídica da compensação ambiental prevista no art. 36 da Lei ${ }^{\circ}$ 9.985/2000, sendo tratada como tributo, preço público, responsabilidade civil antecipada e instrumento econômico decorrente do princípio do poluidor-pagador (FARIAS e ATAIIDE, 2016).

A diversidade de enquadramento quanto a sua natureza jurídica é reflexo da complexidade da matéria abrangida pelo instituto da compensação ambiental. A crescente preocupação com a tutela do meio ambiente natural enseja a criação de medidas adequadas à sua conservação e restauração, que podem gerar dúvidas legítimas sobre como harmonizar interesses e direitos igualmente protegidos pelo Estado.

Bechara (2007, p. 194) aduz que a "natureza jurídica de um instituto revela a que regime jurídico-normas e princípios - ele se submete". Nesse mesmo sentido, Priscila Santos Artigas (2011) afirma que o estudo da natureza jurídica da compensação ambiental busca situar o instituto no arcabouço normativo brasileiro, a fim de viabilizar sua implementação e aplicação prática, ou, em outros termos, permitir a validade e a eficácia da obrigação.

Isto posto, passa-se a discorrer sobre as principais correntes doutrinárias que se dedicam a essa tão importante tarefa, que em muito contribuem para a compreensão da matéria.

\subsubsection{A compensação ambiental como tributo}

Uma primeira posição doutrinária sustenta que compensação ambiental possui natureza tributária, porque a sua estrutura reflete o 
conceito de tributo positivado pelo legislador no art. 3 . $^{\circ}$ da Lei n ${ }^{\circ}$ 5.172/1966 (Código Tributário Nacional - CTN).

Isto é, a exação prevista do art. $36, \S 1 .^{\circ}$, da Lei n ${ }^{\circ} 9.985 / 2000$, trata-se de uma exigência (i) compulsória; (ii) pecuniária, com valor expresso em moeda; que (iii) não constitui sanção de ato ilícito, mas, ao contrário, o fato gerador é atividade empresarial lícita; (iv) foi instituída em lei; e (v) far-se-á por atividade administrativa vinculada (MILARÉ e ARTIGAS, 2006). Em análise mais detida, William Afonso Ogawa demonstra que:

a compensação ambiental objetiva fornecer meios financeiros ao Estado para atingir os seus objetivos de preservação e retira recursos financeiros do empreendedor, portanto, é prestação pecuniária; como a arrecadação da compensação é obrigatória, quando caracterizada a atividade impactante, ela é compulsória; a compensação é arrecadada em dinheiro ou pode ser eventualmente aceita em unidades de serviço, caracterizando "moeda ou valor que nela possa se exprimir"; a compensação não provém de ato ilícito, pois decorre de ato de licenciamento ambiental, plenamente legal; a compensação é instituída no art. 36 da Lei nº 9.985/200; por fim, pode-se verificar que a compensação é cobrada mediante atividade plenamente vinculada, pois a Lei do SNUC estabelece quem deve e como deve ser cobrada a compensação ambiental, uma vez configurada a necessidade de compensação não cabe ao IBAMA apreciar a conveniência (ato discricionário) ou a oportunidade (ato arbitrário) de agir. (OGAWA, 2010, p.29).

Diante dessas evidências, José Marcos Domingues (2009, p. 134) declara que "a verdadeira natureza jurídica do instituto [...] é tributária". Seguindo essa linha, Sidney Guerra e Sérgio Guerra (2012, p. 169) consideram que, dentre "as espécies de tributos previstos na Constituição Federal, é plausível inferir pelo enquadramento da exação em comento como sendo [...] uma contribuição".

Ainda na avaliação de Sidney Guerra e Sérgio Guerra (2012), o desenvolvimento de atividade econômica em desacordo com os princípios constitucionais aos quais está submetida enseja a intervenção da União, que no caso dos empreendimentos de significativo impacto ambiental pode se dar pela instituição de uma contribuição, designada pela doutrina como uma CIDE ambiental.

Compartilham da mesma opinião, Milaré e Artigas (2006, [s.p]), ao sustentarem que a espécie tributária à qual melhor se subsume 
a compensação ambiental é a contribuição de intervenção no domínio econômico (CIDE), que tem fundamento no art. 149 da CF/1988, e cuja função é criar "estímulo ao desenvolvimento de setores da economia nos quais a intervenção estatal seja necessária, onde se enquadra a questão da defesa ao meio ambiente, vislumbrada como princípio da ordem econômica constitucional".

Contudo, embora doutrinadores influentes opinem pela natureza tributária da compensação, prevalece o consenso de que existem dificuldades para subsumir a compensação ambiental a uma espécie de tributo. Na contundente análise de Artigas (2011, p. 62), essas dificuldades "parecem decorrer ora de uma falha da lei que a instituiu ou um déficit de qualidade legislativa, ora da transgressão de diversos princípios e normas que regem a ordem normativa".

Tal realidade abre espaço para críticas por parte da doutrina que descarta a natureza tributária da compensação. Essa é a posição de Costa e Mota (2010, [s.p]), que desconsideram até mesmo a possibilidade de se tratar de tributo disfarçado ou oculto, assim entendido como a "prestação pecuniária que, não obstante albergue todos os elementos essenciais do conceito de tributo na Teoria Geral do Direito, é exigida pelo Estado sem obediência às normas e princípios que compõem o regime jurídico do tributo". Argumentam que a natureza tributária sucumbe aos seguintes critérios de análise:

- quando o empreendedor requer o licenciamento de um empreendimento junto ao órgão/entidade ambiental, a Administração Pública está exercendo o poder de polícia, visto que o ato administrativo vinculado - licenciamento - necessita ter os seus requisitos legais preenchidos, ou seja, competência, finalidade, forma, motivo e objeto em consonância com os princípios insculpidos no art. 37 da CF/1988 (LGL $\backslash 1988 \backslash 3)$;

- não se confunde compensação ambiental com contraprestação efetiva de serviço público, tendo em vista referir-se a uma indenização prévia por meio da qual se busca a reparação do dano originado por um empreendimento causador de significativo impacto ambiental, tendo como parâmetro o EIA/RIMA;

- não há violação do inc. II do art. 145 da CF/1988 (LGL\1988\3), portanto, uma vez que a natureza jurídica da compensação ambiental não se caracteriza como taxa, não devendo existir uma efetiva cobrança e nem uma contraprestação de serviço público habitual;

- a partir do conceito de tributo, cabe esclarecer que na compensação ambiental não 
é necessário ocorrer o ato ilícito, pois a prestação não é compulsória, uma vez que só será exigida nos termos do art. 36 da Lei n 9.985/2000. Portanto, se comparada a definição com os pressupostos da compensação ambiental, constata-se que esta tem natureza reparatória, sendo devida antes de se verificar o dano, pela só obtenção da licença ambiental;

- o valor cobrado na compensação é um valor tecnicamente apurável que não comporta indivisibilidade e especificidade, porque o Estado, neste caso, não está oferecendo uma contraprestação, e sim o empreendedor o está ressarcindo pela utilização dos recursos naturais finitos que pertencem à coletividade, devido à extrapolação no uso desses. (COSTA e MOTA, 2010, [s.p]).

Finalmente, Ana Alice Moreira de Melo (2011), embora reconheça a viabilidade de uma tributação com fins ambientais por meio da instituição de uma CIDE, acredita que a União não intencionou, quando da criação da compensação ambiental, intervir no domínio econômico regulando determinada atividade.

O objetivo do legislador teria sido aplicar o princípio do usuário-pagador, como forma de obrigar os empreendedores a compensar os impactos negativos não mitigáveis ao meio ambiente, e, com isso, promover o desenvolvimento sustentável. "Logo, não há como se atribuir à compensação natureza tributária, tampouco confundi-la com a chamada CIDE” (MELO, 2011, p. 78).

\subsubsection{A compensação ambiental como preço público}

José Marcos Domingues (2006), citado por Bechara (2007, p. 220), conceitua preço público como receitas originárias que

Destinam-se a remunerar a aquisição do direito de propriedade ou de uso e gozo efetivo de bens públicos - patrimônio do Estado (bens materiais), assim como serviços públicos (bens imateriais) efetivamente prestados sem caráter de compulsoriedade (DOMINGUES, 2006, apud BECHARA, 2007, p. 220)

Dito de outra forma, trata-se da denominação dada à remuneração paga ao Poder Público, "pela exploração do patrimônio público, ou pela prestação de um serviço público, não especialmente estatal, vale dizer, uma atividade de natureza comercial ou industrial" (GUERRA, Sidney e GUERRA, Sérgio, 2012, p. 166). Contudo, continuam os autores, 
não parece ser dita compensação ambiental um preço público, pois, a bem da verdade, o que se pretende com a citada compensação não é cobrança pelo uso de um bem público, mas, sim, a imposição de uma obrigação a título de recuperação de um dano ainda não ocorrido (GUERRA, Sidneye GUERRA, Sérgio, 2012, p. 167).

Mesma é a opinião de Bechara (2007, p. 220), visto que "para a compensação ambiental ter a natureza jurídica de serviço público, deveria ela corresponder a uma remuneração paga pelo empreendedor pela utilização dos recursos ambientais". Efetivamente, "o pressuposto da compensação ambiental é o impacto ambiental negativo não mitigável, e não o uso de bens ambientais" (PULSEN, 2007, p. 35, apudMACIEL, 2012, p. 102).

\subsubsection{A compensação ambiental como responsabilidade civil antecipada}

Há importante corrente doutrinária que trata a compensação ambiental no âmbito da responsabilidade civil, consistente na antecipação do dever de reparar o dano presumido. Adotam essa posição, entre outros: Erika Bechara; Marcelo Abelha Rodrigues; Solange Teles da Silva e Willian Afonso Ogawa (Maciel, 2012).

Sobre o embasamento legal da doutrina que pugna pelo enquadramento da compensação ambiental como forma deresponsabilização antecipada do dano, Milaré e Artigas aduzem que

[...] a Constituição Federal, no capítulo relativo ao meio ambiente, impôs ao explorador de recursos naturais a obrigação de recuperar o meio ambiente degradado (art. $225 \S 2 .^{\circ}$ ), bem como, a quem quer que adote condutas lesivas ao meio ambiente, a obrigação de reparar os danos (art. $225 \S 3^{\circ}$ ). Também se mencionou que, ainda antes, a Lei $n^{\circ} 6.938 / 81$ impusera ao poluidor a obrigação de indenizar ou reparar os danos causados por sua atividade, independente da existência de culpa (art. $14 \S 1 .^{\circ}$ ), introduzindo, assim, a responsabilidade objetiva no ordenamento jurídico brasileiro (hoje também prevista no Código Civil de 2002). Partindo dessas proposições é que se sustenta que a natureza jurídica da compensação ambiental se enquadra no instituto da reparação civil, sendo uma forma de reparação pelos danos ocasionados ao meio ambiente (MILARÉ e ARTIGAS, 2006, [s.p]).

Não é o caso, contudo, de classificação incontroversa. Sildaléia Silva Costa (2007, p. 62) indica uma das fontes da celeuma, que reside, 
o principal fundamento jurídico que obriga o causador do dano ambiental à reparálo advém da possibilidade de sua responsabilização, seja penal, administrativa e/ ou civil, conferida pela lei, sendo necessária, no entanto, a ocorrência efetiva do dano para viabilizá-la. No caso da compensação ambiental prevista no art. 36 do SNUC, todavia, está-se diante de um dano potencial, ainda não ocorrido, por meio do qual surge a obrigação de pagamento de um montante de recursos ainda na fase de licenciamento ambiental do empreendimento, como forma de compensar os impactos negativos não mitigáveis identificados no respectivo EIA/RIMA, conforme estabelece a Lei. Destarte, o direito do Estado de exigir o cumprimento desta prestação por parte do empreendedor deriva de obrigação jurídica e não de responsabilidade jurídica, sendo esta uma das principais características do instituto. (COSTA, 2007, p. 62).

\title{
Mauricio Mota descarta a natureza jurídica identificada com a ideia da responsabilidade civil na modalidade reparação de danos antecipada.O autor refuta essa tese argumentando que
}

\begin{abstract}
o dano ambiental futuro, na perspectiva da responsabilidade civil, é a expectativa de dano de caráter individual ou transindividual ao meio ambiente. Por se tratar de risco, não há dano atual nem certeza científica absoluta de sua ocorrência futura, mas tão-somente a probabilidade de dano às futuras gerações. [...] A atribuição de responsabilização civil objetiva funda-se na teoria do risco concreto, que exige a concretização de danos atuais e concretos. [...] Pensar em responsabilidade civil nessa hipótese significaria cogitar de uma responsabilização fundada na formação de uma nova teoria do risco, o risco abstrato, em que as decisões jurídicas tivessem como problema a produção de riscos, e cujo único elemento passível de avaliação consistisse nas probabilidades ou improbabilidades de seu potencial lesivo. A toda evidência, a matéria, embora tenha contatos com a noção de responsabilidade civil, visa coisa diversa: a precaução e prevenção do dano ambiental ainda não ocorrido (MOTA, 2015, p. 793-794).
\end{abstract}

Bechara (2007, p. 233) reconhece que não há reparação sem dano, e que, à vista disso, "a reparação prévia, antes da ocorrência do dano, é incomum para o sistema da responsabilidade civil".

Contudo, sustenta a autora que a responsabilidade civil decorre do dano, não havendo que se falar em responsabilidade civil em função dos riscos (aos quais se aplicam o princípio da prevenção e da precaução). Para 
Bechara (2007, p. 234), "o sistema da responsabilidade civil comporta a reparação de danos futuros, ainda não causados, porém de ocorrência certa, devidamente antevista".

Fazendo coro à Bechara, Marcelo Abelha Rodrigues (2007), assevera que a discussão sobre o dever de ressarcir danos futuros já se encontra superada, como revela cabalmente a disciplina dos lucros cessantes. O fato gerador da obrigação de reparar é a certeza do dano, que pode ser atual ou futuro. Isto é:

dano certo é o dano ocorrido ou o que é seguro e evidente que ocorrerá. A certeza do dano permite que danos que ainda não ocorreram, mas que têm a ocorrência prevista com razoável grau de probabilidade, também devem ser objeto de reparação. Observe-se, ainda, que a certeza do dano advém de estudo completo, baseado em dados técnicos fornecidos por equipe multidisciplinar e contrastados com análises do órgão ambiental no procedimento de EIA-RIMA. Portanto, existe base técnica sólida que permite afirmar que os danos ambientais ocorrerão com aquela obra ou atividade (RODRIGUES, 2007, [s.p]).

O autor conclui seu raciocínio, ao sustentar que, em obediência aos princípios da prevenção e da precaução, não se admite negociar os riscos ao meio ambiente, de modo que cabe ao empreendedor, e não à sociedade, suportar de forma antecipada os riscos de prejuízo pela atividade. Pensar o contrário coloca em dúvida a própria função do EIA-RIMA.

\subsubsection{Compensação ambiental como instrumento econômico decorrente do princípio do poluidor-pagador}

Outra posição que pode ser defendida quanto à natureza jurídica da compensação ambiental é a que considera que a sua característica fundamental é a "preponderância do aspecto econômico, caracterizando-a como instrumento econômico fundado no princípio do poluidor-pagador" (MACIEL, 2012, p. 110). A esse respeito, Vinicius Freitas Lott explica que

a Constituição Federal, no parágrafo único de seu art. 170, assegura que todos têm o livre exercício sobre qualquer atividade econômica, independente da autorização de órgãos públicos, exceto para os casos previstos em lei. No entanto, o mesmo artigo 170 da Constituição afirma que a ordem econômica observará os princípios da defesa do meio ambiente. Quando os custos da degradação ecológica não são pagos por 
aqueles que a geram, estes custos são externalidades para o sistema econômico, os custos afetam terceiros sem a devida compensação (LOTT, 2009, p. 2937).

Para Ronaldo Seroa da Motta, quando empreendimentos são planejados sem considerar as externalidades ambientais

[...] os padrões de consumo das pessoas são forjados sem nenhuma internalização dos custos ambientais. O resultado é um padrão de apropriação do capital natural onde os benefícios são providos para alguns usuários de recursos ambientais sem que estes compensem os custos incorridos por usuários excluídos. Além disso, as gerações futuras serão deixadas com um estoque de capital natural resultante das decisões das gerações atuais, arcando os custos que estas decisões podem implicar (MOTTA, 1997, p. 3)

Dessa forma, Farias e Ataíde (2016) defendem que a compensação ambiental constitui-se em dever fundamental, com natureza jurídica de instrumento econômico decorrente do princípio do poluidor-pagador, na medida em que há a internalização de custos pelo empreendedor. Assim, de modo efetivo, o art. 36 da Lei n ${ }^{\circ}$ 9.985/2000,

ao estabelecer que o empreendedor destinará parte dos recursos da execução da obra ou atividade para a implantação e manutenção de UCs, acaba promovendo a internalização de custos relativos aos impactos ambientais negativos não mitigáveis aos recursos naturais, no custo do empreendimento (MACIEL, 2012, p. 110).

Afinal, a compensação ambiental não visa reparar danos, nem mesmo a simples compensação de impactos, pois incentiva a sua redução. "Seu escopo é, portanto, preventivo, orientado para o futuro, e não reparatório, voltado para o passado" (MACIEL, 2012, p.111).

Dentre as correntes expostas, o presente trabalho inclina-se pela adoção da que entende ser a compensação ambiental um instrumento econômico decorrente do princípio do usuário/poluidor-pagador, cuja principal característica é integrar o planejamento econômico de atividades causadoras de significativos impactos ambientais, de modo a favorecer a internalização de custos ambientais e, com isso, buscar a compatibilização entre o desenvolvimento econômico e a manutenção da qualidade do meio ambiente e do equilíbrio ecológico.

De toda forma, percebe-se que as tentativas de enquadrar a 
natureza jurídica da compensação ambiental aos institutos já existentes não são bem sucedidas. Isso ocorre em virtude de se tratar de uma invenção brasileira relativamente nova (FARIAS e ATAÍDE, 2016, [s.p]). Entretanto, o fundamental, na observação de Sílvia Capelli, é que

o dano seja reparado na sua integralidade. Aqui não importa o debate sobre a natureza jurídica da compensação da Lei do SNUC, pois independentemente da opção que se adote, sempre haverá obrigação constitucional de reparar integralmente o dano ao meio ambiente. Assim, não há qualquer óbice à cumulação da compensação prevista no SNUC, com a compensação ambiental por equivalente ecológico (in natura ex situ), ou ainda, com indenização, diante de um dano total ou parcialmente irreversível. Tal cumulação é decorrência do princípio da reparação integral do dano e de mandamento constitucional (CAPELLI, 2011, p. 367).

Ademais, soma-se às correntes precitadas a inaugurada pelo Supremo Tribunal Federal (STF) por ocasião do julgamento da Ação Direta de Inconstitucionalidade (ADI 3.378/DF), segundo a qual a compensação ambiental é uma forma de compartilhamento de despesas com as medidas oficiais de específica prevenção em face de empreendimentos com significativos impactos ambientais.

Ressalva-se,porém, ofatodequeodenominado "compartilhamento de despesas não se refere exatamente a uma natureza jurídica, mas ao próprio objetivo [...] da obrigação" (Artigas, 2011, p. 70), como se verá a seguir.

\section{POSSIBILIDADE JURÍDICA DA INSTITUIÇÃO DA COMPENSAÇÃO AMBIENTAL MUNICIPAL POR IMPACTOS NÃO MITIGÁVEIS DE MÉDIA MAGNITUDE}

De início, reitera-se que o objetivo precípuo do presente trabalho é propor uma ampliação, no âmbito municipal, do regime de proteção atualmente dispensado ao meio ambiente quando do licenciamento de atividades potencialmente poluidoras e utilizadoras de recursos naturais.

Tal pretensão se realizaria, acredita-se, pela instituição de uma espécie de compensação ambiental prévia, expressa em valores pecuniários, exigida legalmente em casos de atividades passíveis de licenciamento, e que provoquem impactos negativos não mitigáveis de média magnitude, assim considerados pelo órgão ambiental local, com base em estudos 
ambientais e regulamentação específica.

Dentre as espécies de compensação ambiental previstas na legislação brasileira, já revisadas em capítulo anterior, a que mais se aproxima da compensação ambiental municipal proposta neste estudo, funcionando, portanto, como paradigma, é positivada no art. 36 da Lei $\mathrm{n}^{\circ}$ 9.985/2000, destinada ao financiamento do Sistema Nacional de Unidades de Conservação (SNUC).

O paralelo pode ser traçado com base em características comuns, tais como: (a) se tratarem de compensação exigida "na fase do juízo de viabilidade da atividade ou empreendimento" (MILARÉ, 2016, p. 241), e portanto antes da efetivação do dano ambiental, independente de conduta ilícita; (b) ser expressa em valores pecuniários; (c) instituída por lei; e (d) com fundamento no princípio do usuário pagador, cuja finalidade é criar mecanismos de internalização dos impactos negativos não mitigáveis decorrentes de atividade passível de licenciamento ambiental.

Distinguem-se, por outro lado, no que concerne às hipóteses de incidência, em função da grandeza do impacto negativo definida como requisito para a constituição da obrigação de compensar, do tipo de estudo ambiental exigido, bem como pelo alcance territorial da norma.

Dito de forma mais detalhada, temos que a compensação ambiental federal requer, dentre outros requisitos, a existência de significativo impacto ambiental, assim considerado pelo órgão ambiental competente com base em EIA/RIMA, enquanto a compensação ambiental municipal atuaria em um nível mais restritivo, sendo imposta no caso de impacto negativo de média magnitude, conforme apurado pelo órgão ambiental local, devidamente subsidiado por estudo ambiental e regulamento próprio.

Note-se que a expressão "estudo ambiental" tem sentido amplo, não havendo, na proposta, limitação quanto à tipologia de estudo que subsidiará a imposição da exação. Em sentido oposto, a compensação do SNUC apenas admite para a caracterização da compensação ambiental EIA/RIMA, instrumento de avaliação de impacto ambiental previsto na $\mathrm{CF} / 1988$ (Artigo 225, § $1^{\circ}$, inciso IV), "específico para obras ou atividades potencialmente causadoras de significativa degradação do meio ambiente" (MOTTA, 2013, p. 41), a exemplo das relacionadas no art. $2^{\circ}$ da Resolução Conama ${ }^{\circ}$ 001, de 23 de janeiro de 1986.

Nesse sentido, o presente trabalho se alinha à posição de Erika Bechara, a qual considera que 
se aideia da compensação é "oferecer algo em troca" de danos irreparáveis constatados previamente à implantação do empreendimento, tanto faz se o empreendimento está sujeito ou não ao EPIA/RIMA - importa, isso sim, que o órgão ambiental detecte a irreversibilidade de algum dano no licenciamento ambiental de obra ou atividade. (BECHARA, 2007, p. 314).

Como pode ser depreendido do trecho citado, a autora entende devida a compensação ambiental sempre que se constatar dano ambiental irreversível. Embora se admita essa possibilidade, a proposta debatida neste estudo limita-se à compensação dos danos de média magnitude. Essa posição tem viés pragmático, tendo em vista que eventual proposta de instituição de compensação ambiental por impactos de baixa magnitude possivelmente será interpretada como excessivamente restritiva pela classe política e por setores produtivos dos municípios que em dado momento iniciem um debate sobre o tema.

Por sua vez, alcance territorial nada mais é do que uma decorrência da natureza do ente político do qual emana a norma. Enquanto a União edita lei válida em todo o território nacional, a atividade legiferante do município não produz efeitos diretos para além de seus limites geográficos. Isto é, enquanto a compensação ambiental do SNUC é norma cogente em todo o Brasil, a compensação municipal vincula apenas as atividades locais, em respeito à autonomia e harmonia entre os entes federados.

Em vista do exposto, ao mesmo tempo que a compensação ambiental municipal compartilha da essência compensação SNUC, que é a manutenção do equilíbrio ecológico pela internalização dos custos ambientais, distingue-se da mesma, porquanto os elementos caracterizadores da exação não são coincidentes, embora próximos.

Ademais, "os empreendimentos e atividades são licenciados ou autorizados, ambientalmente, por um único ente federativo", conforme previsão do art. 13 da Lei Complementar $n^{\circ}$ 140/2011, fato que, somado às distinções já debatidas, afasta a possibilidade de que a instituição da pretendida compensação ambiental municipal represente uma violação ao Sistema Nacional de Unidades de Conservação.

O que se verifica, aliás, é uma ampliação do regime de proteção ao meio ambiente natural. Isso porque, sempre que se verificarem, cumulativamente, licenciamento ambiental; Estudo de Impacto Ambiental e respectivo Relatório de Impacto Ambiental - EIA/RIMA; além da identificação pelo órgão ambiental de significativos impactos negativos 
não mitigáveis, incidirá a compensação prevista no art. 36 da Lei ${ }^{\circ}$ 9.985/2000.

Com efeito, conforme anotado por Ana Alice Moreira de Melo (2011, p. 49), o art. 36 da Lei $\mathrm{n}^{\circ}$ 9.985/2000 "caracteriza verdadeira norma geral sobre responsabilidade por dano ambiental, conservação da natureza, proteção do meio ambiente e controle da poluição", de tal forma que eventual não aplicação pelos Estados-Membros "constitui [...] clara desobediência ao princípio constitucional da supremacia da norma geral federal em matéria ambiental previsto no artigo 24 da Carta Magna" (2011, p. 51), cabendo a estes a regulamentação da matéria no âmbito de sua jurisdição, suplementando a legislação federal de forma a melhor adaptála às suas necessidades.

Ressalva-se que, embora a autora tenha focado sua análise na competência legislativa dos Estados, aos municípios também está reservada a possibilidade de regulamentar o art. 36 da lei do SNUC.Como já debatido, inobstante o silêncio do art. 24 da Constituição Federal em relação à competência legislativa concorrente dos municípios, estes a possuem em função de sua competência para legislar sobre assuntos de interesse local (art. 30, I) (FIGUEIREDO, 2011).

Conforme observação de Sinara Soares (2013, [s.p]), a Lei n ${ }^{\circ}$ 9.985/2000 e o Decreto 4.340/2002,

estabeleciam que a competência para a fixação da compensação do Snuc seria do "órgão ambiental" competente para o licenciamento ambiental, ou seja, não havia, no texto legal, distinção expressa de qual órgão licenciador seria competente para a cobrança da compensação (SOARES, 2013, [s.p]).

Contudo, segundo a autora, desde a edição do Decreto $\mathrm{n}^{\circ} 6.848$, passou a existir uma clara "limitação natural do âmbito de aplicação da compensação Snuc aos empreendimentos sujeitos a licenciamento pelo Ibama". Além disso, os recursos advindos da aplicação da Lei no 9.985/2000 pressupõem uma receita pública federal, de modo que,

determinado Estado ou Município não poderia pretender aplicar uma compensação Snuc local, com base na lei federal. Para que pudesse ser estabelecida a obrigação de pagamento de uma compensação ambiental no âmbito estadual, far-se-ia necessária previsão em lei estadual, sob pena de violação do princípio da autonomia financeira local (arts. 24 e 30 da CF (LGL\1988\3)) (SOARES, 2013, [s.p]). 
Isto posto, firma-se o entendimento de que a aplicação da compensação federal por um órgão ambiental local deve ser precedida por sua regulamentação por lei municipal. Isso não significa, entretanto, que não se possa editar lei municipal que trate exclusivamente da compensação por impactos não mitigáveis de média magnitude na forma proposta neste trabalho.

Como visto, eventual instituição pelo município de compensação ambiental dessa natureza não tem por objetivo suprimir a aplicação da compensação federal, norma geral de aplicação obrigatória sempre que se configurarem as hipóteses de incidência narradas no art. 36 da Lei ${ }^{\circ}$ 9.985/2000. A compensação municipal nada mais é do que um ampliação do regime de proteção oferecido pela norma geral, e operaria independente desta, vez que compartilham do mesmo fundamento, mas não do mesmo fato gerador da obrigação.

Dito isto, a compensação ambiental municipal apenas seria devida quando órgão ambiental municipal, no curso de processo de licenciamento ambiental de atividades que "causem ou possam causar impacto ambiental de âmbito local" (art. $9^{\circ}, \mathrm{XIV}, a$, da Lei Complementar $\left.n^{\circ} 140 / 2011\right)$, verificar a existência de impacto ambiental não mitigável de média magnitude.

A definição do que se entende por "média magnitude" representa desafio semelhante ao enfrentado pelo legislador federal, quando, ao editar a Lei $n^{\circ} 9.985 / 2000$, vinculou a obrigação prevista no art. 36 à existência de "significativo impacto ambiental", conceito que igualmente alberga algum nível de discricionariedade.

Tal característica é inerente à disciplina da avaliação de impacto ambiental, que lida com um grande número de variáveis que perpassam múltiplas áreas do conhecimento, o que não justifica, de modo algum, o descarte de iniciativas com potencial de aprimorar a gestão dos recursos ambientais. O que se deve buscar é a redução das discricionariedades por meio da regulamentação e constante aperfeiçoamento das normas destinadas à proteção ambiental, o que no caso da compensação do SNUC se deu com a edição do Decreto $\mathrm{N}^{\mathrm{o}} 4.340$, de 22 de agosto de 2002, posteriormente alterado pelo Decreto $\mathrm{N}^{\mathrm{o}} 6.848$, de 14 de maio de 2009.

Pois bem, a verificação da juridicidade de compensação ambiental municipal nos termos propostos, passa, obrigatoriamente, pela análise da competência legislativa e administrativa em matéria ambiental atribuídas aos referidos entes federados. 
Conforme previamente debatido, "o princípio da autonomia municipal encontra seu fundamento legal nos arts. 29 e 30 da CF/1988 (LGL\1988\3), que determinam ao Município, entre outras coisas, reger-se por lei orgânica, [...] e legislar sobre matéria de interesse local" (SILVEIRA, 2005, [s.p]). Já as competências administrativa e legislativa estão pactuadas, respectivamente, nos arts. 23 e 24 da CF/1988.

Ocorre que, embora seja reservada ao município posição de destaque dentro da federação, gozando de grande autonomia, "talvez por conta de uma exegese equivocada, ou em razão de heranças autoritárias e, consequentemente, um federalismo mitigado, ainda hoje a autonomia municipal não vem sendo respeitada e aplicada integralmente como prevê a Constituição em vigor" (SILVEIRA, 2005, [s.p]).

No mesmo sentido é a crítica de ToshioMukai, que reputa "pobre, quando não nula, a existência de legislações municipais a respeito da proteção ambiental. A que se deve tal fenômeno, quando se sabe que o Município, no Brasil, é autônomo, política e administrativamente?" (MUKAI, 2011, [s.p]).

Respondendo à própria indagação, supõe o autor que, aparentemente, "os administradores e legisladores municipais, eles próprios, se julgam sem competência legal no campo da proteção ambiental, porque veem especialmente nos últimos anos, a União e os Estados com o quase monopólio dessa atividade" (MUKAI, 2011, [s.p])

Para agravar tal situação, muitas vezes essa inércia legislativa é quebrada para a defesa de "interesse local pelo desenvolvimento econômico não sustentado ou imediatista, em antagonismo com o interesse local, pela conservação do meio ambiente" (MACHADO, 2013, p. 443).

Não é, contudo, o que se presente propor com o presente trabalho. Entende-se configurado o interesse local para legislar sobre a proteção do meio ambiente, com claro efeito benéfico ao equilíbrio ecológico, proporcionado por norma mais restritiva que a congênere de aplicação geral, sem contudo, excluir a aplicação desta última.

Defende-se, por todo o exposto, a juridicidade da compensação ambiental objeto deste trabalho, tendo em vista que

o Município, dentro de sua autonomia constitucional para legislar em matéria administrativa, e para atuar em consequência, no exercício do seu poder de polícia, pode restringir liberdades, atividades e até mesmo a propriedade, em benefício da coletividade local, visando proteger a saúde, o meio ambiente e até mesmo a vida 
dos munícipes. Pode e deve, posto que se trata aí do desenvolvimento do princípio do poder-dever do administrador público (MUKAI, 2011, [s.p]).

Não por acaso, o Supremo Tribunal Federal, em sede da ADI 3.378/DF, reconheceu a constitucionalidade da compensação ambiental da Lei $n^{\circ} 9.985 / 2000$, uma vez que a mesma "densifica o princípio usuário-pagador, este a significar um mecanismo de assunção partilhada da responsabilidade social pelos custos ambientais derivados da atividade econômica" (BRASIL, 2008, p. 242).

Finalmente, como se nota, afora a inequívoca competência do município para instituir a obrigação, em estrita observação a interesse local e em consonância com as disposições dos arts. 23 e 24 da CF/1988, os fundamentos que justificaram a validação da norma federal são os mesmos que informam a proposta de compensação ambiental municipal por impactos não mitigáveis de média magnitude, o que acaba por revelar a sua compatibilidade com a ordem constitucional vigente.

2.1. Formas alternativas da destinação dos recursos

Paraalémdapossibilidadedeinstituiçãodacompensaçãoambiental municipal, o presente trabalho pugna por uma ampla discricionariedade na aplicação do recursos arrecadados, da qual se serviria o gestor público para patrocinar projetos e ações de recuperação ambiental, com a condição de contribuírem para a manutenção do equilíbrio ecológico, em sintonia com as disposições constitucionais que dão contorno à matéria.

A Lei $n^{\circ} 9.985 / 2000$, por meio de seu art. 36, determina que os recursos oriundos da compensação ambiental sejam destinados à implantação e manutenção de unidades de conservação do Grupo de Proteção Integral, composto pelas categorias elencadas no art. $8^{\circ}$, incisos I a V.

Excepcionalmente autoriza que parte dos recursos beneficie unidades de conservação do Grupo de Uso Sustentável, descritas no art. 14, incisos I a VII, com a condição de sejam afetadas pelo empreendimento licenciado (art. $36, \S 3^{\circ}$ ), como pode ser verificado a seguir:

Art. 36. Nos casos de licenciamento ambiental de empreendimentos de significativo impacto ambiental, assim considerado pelo órgão ambiental competente, com fundamento em estudo de impacto ambiental e respectivo relatório - EIA/RIMA, o empreendedor é obrigado a apoiar a implantação e manutenção de unidade de conservação do Grupo de Proteção Integral, de acordo com o disposto neste artigo e 
no regulamento desta Lei. [...]

$\S 3^{\circ}$. Quando o empreendimento afetar unidade de conservação específica ou sua zona de amortecimento, o licenciamento a que se refere o caput deste artigo só poderá ser concedido mediante autorização do órgão responsável por sua administração, e a unidade afetada, mesmo que não pertencente ao Grupo de Proteção Integral, deverá ser uma das beneficiárias da compensação definida neste artigo.

De forma resumida, pode-se afirmar que "a lei atrela inteiramente a compensação ambiental às unidades de conservação. E, preferencialmente, às unidades de conservação de proteção integral" (BECHARA, 2007, p. 295).

Como resultado dessa limitação, o que se observa é que a administração pública vê-se obrigada a aplicar todo o montante financeiro desembolsado pelos empreendedores em ações que, eventualmente, podem não produzir, dentre os cenários possíveis, os serviços ecológicos aptos a fornecer o maior incremento à qualidade ambiental observada em determinada localidade. Dessa forma, por não observar o critério da preponderância do interesse local, questiona-se

[...] se compensação ambiental deveria ficar adstrita à criação e implantação de unidades de conservação, considerando a possibilidade de se proporcionar ganhos ambientais à coletividade atingida pelos danos, por inúmeros outros mecanismos, como, v.g, reflorestamento de áreas degradadas e remediação de áreas contaminadas (naturalmente, quando não for possível identificar o poluidor visto que, neste caso, o reflorestamento ou a remediação terão que ser promovidos exclusivamente às suas custas e não às custas dos recursos da compensação) (BECHARA, 2007, p. 296).

Noutra perspectiva, Paulo Affonso Leme Machado (2013, p. 978) também tece sua crítica à aplicação exclusiva dos recursos em unidades de conservação, ao notar que "o pagamento ou a contribuição monetária criada não atinge todos os campos em que possam incidir os efeitos da atividade a ser licenciada", já que "a poluição das águas e da atmosfera, a poluição sonora, a poluição do solo, através de rejeitos e de agrotóxicos não estão abrangidas na compensação a ser paga".

Por certo, a qualidade ambiental de um determinado ecossistema ou região não se resume à criação e manutenção de unidades de conservação. Sem desconsiderar a grande importância que a Constituição Federal conferiu às áreas protegidas, estas não resumem todas as formas de 
se buscar o equilíbrio ecológico. Todavia,

do ponto de vista jurídico [...] fez-se uma opção. Ou seja, partindo-se da constatação de que o investimento em unidades de conservação seria uma forma adequada (embora não única) de compensar os males gerados por uma obra ou atividade degradadora, decidiu o legislador canalizar a compensação para este fim (BECHARA, 2007, p. 296-297).

Marília Passos Torres de Almeida, citada por Erika Bechara, discorda desse modelo, "que prefere a formação e manutenção de 'ilhas isoladas de conservação' ao invés de promover a restauração de um bem diverso mas com funções ecológicas equivalentes ao bem danificado" (TORRES, 2005, p. 324 BECHARA, 2007, p. 297).

Assim, embora se reconheça a singular importância da compensação ambiental instituída pela Lei ${ }^{\circ}$ 9.985/2000, que cumpre um relevante papel na preservação de grandes extensões territoriais, defendese seu aprimoramento por meio da ampliação das hipóteses de incidência e da flexibilização das possibilidades de aplicação dos recursos. Como bem lembrado por Mauricio Mota,

a complexidade do conceito de bem ambiental, seu caráter holístico, irão suscitar novas soluções de direito. Superado o entendimento do meio ambiente como res nullius e revelada a insuficiência da simples patrimonialização pública sem controle de gestão dos usos do bem ambiental, cabe agora repensá-lo a partir de seu escopo, de sua função, protegendo-o em vista de suas finalidades (MOTA, 2015, p. 801).

Ante todo o exposto, entende-se que o vislumbrado aperfeiçoamento poderia operar-se pelo exercício das competências atribuídas aos municípios pela Constituição Federal de 1988.

Isto é, a compensação ambiental municipal, ao ser instituída, além de representar uma ampliação da proteção oferecida pela Lei ${ }^{\circ}$ 9.985/2000, deve permitir ao município, no exercício de sua competência administrativa, definir a forma mais eficiente de alocar os recursos financeiros, sempre com vistas a produzir os benefícios ambientais que melhor representam o interesse local. 


\section{CONCLUSÃO}

A compensação ambiental pode ser compreendida,em sentido amplo, como a substituição de um bem ambiental lesado por outro de valor ecológico equivalente. Trata-se de instituto aplicado de forma subsidiária, sempre que as medidas preventivas se mostrarem insuficientes para evitar a ação danosa e se comprovar a impossibilidade da restauração dos serviços ecológicos antes prestados pelo bem ambiental prejudicado.

Representa, ainda, um importante mecanismo de internalização dos custos ambientais de empreendimentos que provoquem impactos negativos não mitigáveis. Isto é, algumas atividades, embora toleradas em razão dos benefícios sociais que geram, devem, em atenção ao princípio do poluidor/usuário-pagador, aplicar parte do seu orçamento em benefício do meio ambiente.

Referida medida visa impedir a apropriação irrefreada de capital ambiental por particulares, com as externalidades ambientais suportadas exclusivamente pela sociedade. Permite-se, dessa forma, o desenvolvimento econômico, ao mesmo tempo em que se persegue a manutenção do equilíbrio ecológico, conforme preconizado pela Constituição Federal de 1988.

A Lei ${ }^{\circ} 9.985 / 2000$, por meio de seu art. 36, inseriu os custos ambientais no planejamento econômico de atividades que afetam negativamente, e de modo significativo, o meio ambiente natural. Optou a norma federal por utilizar os impactos ambientais negativos irreversíveis, identificados na fase de avaliação de impacto ambiental, a qual deve se dar na forma de EIA-RIMA, como critério para quantificar os recursos financeiros a serem destinados para a criação e manutenção de unidades de conservação.

A opção do legislador foi clara ao destinar os recursos arrecadados exclusivamente ao Sistema Nacional de Unidades de Conservação. Com isso, buscou dar concretude à disposição constitucional segundo a qual cabe ao Poder Público "definir, em todas as unidades da Federação, espaços territoriais e seus componentes a serem especialmente protegidos" (CF/1988, art. 225, § $1^{\circ}$, III).

A Lei $n^{0} 9.985 / 2000$ é norma geral de observação obrigatória pelos Estados e Municípios, mas carece de regulamentação no âmbito de suas respectivas competências, que devem adequá-la às suas necessidades regionais ou locais, vedada a edição de norma menos restritiva. Tem natureza 
jurídica de instrumento econômico decorrente do princípio do usuário/ poluidor-pagador, e teve sua constitucionalidade reconhecida pelo Supremo Tribunal Federal, por densificar o princípio usuário-pagador, funcionado como um mecanismo de assunção partilhada da responsabilidade social pelos custos ambientais derivados da atividade econômica.

Portanto, como ente federativo competente para legislar e atuar administrativamente em matéria ambiental, o município deve, para exigir a exação prevista no art. 36 da Lei $n^{\circ} 9.985 / 2000$, regulamentá-la internamente. No entanto, na defesa de interesse local, pode suplementar a norma federal, e ampliar as hipóteses de cabimento da obrigação. Essa ampliação pode se dar pela exigência de compensação ecológica por impactos não mitigáveis de qualquer magnitude, bem como pela admissão de diversos métodos de avaliação de impacto ambiental, e não exclusivamente EIA-RIMA.

Em que pese a possibilidade de se admitir a compensação por impactos irreversíveis de qualquer grandeza, a opção pugnada pelo presente trabalho é regulação da exigência para aqueles empreendimentos que, embora não se equiparem aos exemplificados no art. $2^{\circ}$ da Resolução Conama $\mathrm{n}^{\circ}$ 001, de 23 de janeiro de 1986, produzem impactos com consequências sensíveis à qualidade do meio ambiente natural, situandose em posição intermediária na escala de empreendimentos potencialmente prejudiciais às condições ecológicas da sua área de influência. É o que se convencionou chamar de impactos não mitigáveis de média magnitude, cuja conceituação deve ser objeto de regulamentação, com vistas a reduzir as subjetividades quando da classificação pelo órgão ambiental.

Ademais, a opção por estender a exigência aos impactos de baixa e média grandeza passa pela avaliação do gestor acerca das diversas variáveis que influenciam a atividade legiferante do município. Possivelmente, de um ponto de vista mais pragmático, eventual proposta de instituição de compensação ambiental por impactos de baixa magnitude será interpretada como excessivamente restritiva pela classe política e por setores produtivos dos municípios.

O que não se pode olvidar, contudo, é que, embora seja desejável que todo impacto ambiental irreversível seja devidamente compensado, a edição de lei municipal destinada a criar mecanismos de compensação dos danos de média grandeza representa grande avanço na gestão e conservação dos recursos naturais locais.

Conclui-se, por fim, pela viabilidade de que os recursos provenientes de compensação ambiental municipal por impactos de média 
magnitude sejam destinados para a restauração das funções ecológicas essenciais à conservação da natureza e à sadia qualidade de vida da população, e não exclusivamente para a criação e manutenção de unidades de conservação.

Assim como o legislador federal optou por privilegiar o Sistema Nacional de Unidades de Conservação, cabe ao município, no exercícios de sua competência legislativa constitucionalmente assegurada, definir as possibilidades de aplicação dos recursos, desde que beneficiem diretamente o meio ambiente natural.

\section{REFERÊNCIAS}

ALMEIDA, Fernando Menezes de; ZAGO, Mariana Augusta dos Santos. O "interesse comum" da região metropolitana em face da repartição constitucional de competências federativas. Revista Brasileira de Advocacia. vol. 3, p. 106 - 138, out - dez / 2016.

ARTIGAS, Priscila Santos. Contribuição ao estudo das medidas compensatórias em direito ambiental. Tese (Doutorado em Direito Econômico e Financeiro). Universidade de São Paulo, 2011.

BARBOSA, Haroldo Camargo. Meio ambiente, direito fundamental e da personalidade da conexão às consequências na reparação. Revista de Direito Ambiental. vol. 68, p. 49 - 74. out - dez / 2012.

BECHARA, Erika. Uma contribuição ao aprimoramento do instituto da compensação ambiental previsto na lei $\mathbf{9 . 9 8 5 / 2 0 0 0}$. Tese (Doutorado em Direito) - Pontifícia Universidade Católica de São Paulo, São Paulo, 2007.

BELTRÃO, Antônio Figueiredo Guerra. A competência dos Estados federados em meio ambiente a partir da ordem constitucional de 1988. Revista de Informação Legislativa. Brasília, a. 40, n. 159, jul - set / 2003.

BRASIL. Decreto Federal $n^{\circ}$ 4.340,de 22 de agosto de 2002. Regulamenta artigos da lei $\mathrm{N}^{\mathrm{0}}$ 9.985, de 18 de julho de 2002, que dispõe sobre o Sistema Nacional de Unidades de Conservação da Natureza - SNUC, e dá outras providências. Disponível em: <http://www.planalto.gov.br/ccivil_03/ decreto/2002/d4340.htm>. Acesso em: 15 mar 2017.

BRASIL.Decreto $\mathbf{n}^{\mathbf{0}} \mathbf{6 . 8 4 8}$, de 14 de maio de 2009 . Altera e acrescenta dispositivos ao Decreto no 4.340, de 22 de agosto de 
2002, para regulamentar a compensação ambiental. Disponível em: $<$ http:// www.planalto.gov.br/ccivil_03/_ato2007-2010/2009/decreto/d6848.htm>. Acesso em: 15 de maio 10 de maio de 2017.

BRASIL.Lei Complementar $\mathbf{n}^{0}$ 140, de 8 de dezembro de 2011. Fixa normas, nos termos dos incisos III, VI e VII do caput e do parágrafo único do art. 23 da Constituição Federal, para a cooperação entre a União, os Estados, o Distrito Federal e os Municípios nas ações administrativas decorrentes do exercício da competência comum relativas à proteção das paisagens naturais notáveis, à proteção do meio ambiente, ao combate à poluição em qualquer de suas formas e à preservação das florestas, da fauna e da flora; e altera a Lei no 6.938, de 31 de agosto de 1981. Disponível em: $<$ http://www.planalto.gov.br/ccivil_03/leis/LCP/Lcp140.htm>. Acesso em: 15 de maio de 2017.

BRASIL.Lei $n^{0} \mathbf{1 1 . 4 2 8}$, de 22 de dezembro de 2006. Dispõe sobre a utilização e proteção da vegetação nativa do Bioma Mata Atlântica, e dá outras providências. Disponível em: <http://www.planalto.gov.br/ ccivil_03/_ato2004-2006/2006/lei/111428.htm>. Acesso em: 16 de mar de 2017.

BRASIL.Lei $\mathbf{n}^{\mathbf{0}} \mathbf{1 2 . 6 5 1}$, de 25 de maio de 2012. Dispõe sobre a proteção da vegetação nativa; altera as Leis nos 6.938, de 31 de agosto de 1981, 9.393, de 19 de dezembro de 1996, e 11.428, de 22 de dezembro de 2006; revoga as Leis nos 4.771, de 15 de setembro de 1965, e 7.754, de 14 de abril de 1989, e a Medida Provisória no 2.166-67, de 24 de agosto de 2001; e dá outras providências. Disponível em: < http://www.planalto.gov.br/ ccivil_03/_ato2011-2014/2012/lei/L12651compilado.htm>. Acesso em: 15 de mar de 2017.

BRASIL.Lei ${ }^{0}$ 4.771, de 15 de setembro de 1965. Institui o novo Código Florestal. Revogada pela Lei $\mathrm{n}^{\circ} 12.651$, de 2012. Disponível em: < http:// www.planalto.gov.br/ccivil_03/leis/L4771.htm>. Acesso em: 15 de mar de 2017.

BRASIL.Lei $\mathbf{n}^{0}$ 5.172, de 25 de outubro de 1966. Dispõe sobre o Sistema Tributário Nacional e institui normas gerais de direito tributário aplicáveis à União, Estados e Municípios. Disponível em: <http://www.planalto.gov. br/ccivil_03/leis/L5172.htm>. Acesso em: 20 de abr de 2017.

BRASIL.Lei ${ }^{0}$ 5.172, de 25 de outubro de 1966. Dispõe sobre o Sistema Tributário Nacional e institui normas gerais de direito tributário aplicáveis à União, Estados e Municípios. Disponível em: <http://www.planalto.gov. 
br/ccivil_03/leis/L5172.htm>. Acesso em: 10 de maio de 2017.

BRASIL.Lei $\mathbf{n}^{\mathbf{0}} \mathbf{6 . 9 3 8}$, de 31 de agosto de 1981. Dispõe sobre a Política Nacional do Meio Ambiente, seus fins e mecanismos de formulação e aplicação, e dá outras providências. Disponível em: $<$ http://www.planalto. gov.br/ccivil_03/leis/L6938.htm>. Acesso em: 12 de mar de 2017.

BRASIL.Lei $n^{0}$ 9.008, de 21 de março de 1995. Cria, na estrutura organizacional do Ministério da Justiça, o Conselho Federal de que trata o art. 13 da Lei $\mathrm{n}^{\circ} 7.347$, de 24 de julho de 1985, altera os arts. $4^{\circ}, 39,82,91$ e 98 da Lei no 8.078 , de 11 de setembro de 1990, e dá outras providências. Disponível em: <http://www.planalto.gov.br/ccivil_03/leis/L9008.htm>. Acesso em: 05 de maio de 2017.

BRASIL.Lei $\mathbf{n}^{\mathbf{0}}$ 9.985, de 18 de Julho de 2000. Regulamenta o artigo 225, § $1^{\circ}$, incisos I, II, III e VII da Constituição Federal, institui o Sistema Nacional de Unidades de Conservação da Natureza e dá outras providências. Ministério do Meio Ambiente, Brasília. Disponível em: < http://www.planalto.gov.br/ccivil_03/leis/L9985.htm>. Acesso em: 15 de fev de 2017.

BRASIL.Lei $\mathbf{n}^{\mathbf{0}} \mathbf{7 . 3 4 7}$, de 24 de julho de 1985. Disciplina a ação civil pública de responsabilidade por danos causados ao meio-ambiente, ao consumidor, a bens e direitos de valor artístico, estético, histórico, turístico e paisagístico (vetado) e dá outras providências. Disponível em: < http:// www.planalto.gov.br/ccivil_03/leis/L7347orig.htm>. Acesso em: 05 de maio de 2017.

BRASIL.Supremo Tribunal Federal. Tribunal Pleno. Ação Direta de Inconstitucionalidade $\mathbf{n}^{\mathbf{0}} \mathbf{3 . 3 7 8} / \mathrm{DF}$. Proponente: Confederação Nacional da Indústria. Requeridos: Presidente da República; Congresso Nacional. Carlos Ayres Britto (relator). Julgamento:09 de abr. 2008. Disponível em: $\quad<$ http://redir.stf.jus.br/paginadorpub/paginador. jsp?docTP=AC\&docID=534983>. Acesso em: 15 de abr. de 2017.

Constituição Federal de 1988. Promulgada em 5 de outubro de 1988. Disponível em <http://www.planalto.gov.br/ccivil_03/constituicao/ constituicao.htm>. Acesso em: 02 fev. 2017.

BURGONOVO, Ivan. Competência executiva comum em matéria ambiental. Dissertação (Mestrado em Ciência Jurídica). Universidade do Vale do Itajaí, 2014. 
CAPELLI, Sílvia. Compensação Ambiental do Sistema Nacional de Unidades de Conservação: considerações pós-decisão do STF na ADI 3378. Lusíada: Direito e Ambiente, Lisboa, $\mathrm{n}^{\circ}$. 2, mar. de2011.

CONAMA. Resolução $\mathbf{n}^{0}$ 01, de 23 de janeiro de 1986. Dispõe sobre critérios básicos e diretrizes gerais para o Relatório de Impacto Ambiental - RIMA. Disponível em: <http://www.mma.gov.br/port/conama/legiabre. cfm?codlegi=23>. Acesso em: 04 mar de 2017.

COSTA, Sildaléia Silva. Compensação ambiental: uma alternativa de recursos para implementação do Sistema Nacional de Unidades de Conservação da Natureza (SNUC). Dissertação (Mestrado em Políticas Públicas e Gestão Ambiental do Centro de Desenvolvimento Sustentável) - Universidade de Brasília, 2007.

COSTA, SildaléiaSilva; MOTA, José Aroudo. Compensação ambiental: uma opção de recursos para implementação do Snuc. Revista de Direito Ambiental. vol. 58, p. 174 - 205, abr - jun / 2010.

DOMINGUES, José Marcos. O Supremo Tribunal e a compensação SNUC. A ADI 3.378-DF. Revista Direito GV, São Paulo, v. 5, n. 1, p. 125-146, jan - jun / 2009.

FARIAS, Talden. Competência legislativa em matéria ambiental. Revista Jus Navigandi, Teresina, ano 12, n. 1405, 7 maio de 2007. Disponível em: $<$ https://jus.com.br/artigos/9811>. Acesso em: 20 abr. 2017.

FARIAS, Talden. Licenciamento ambiental: aspectos teóricos e práticos. 4. ed. Belo Horizonte: Fórum, 2013. 212 p.

FARIAS, Talden; ATAÍDE, Pedro Henrique Sousa de. A compensação ambiental do art. 36 da Lei 9.985/2000: aspectos conceituais e questões controvertidas. Revista de Direito Ambiental, vol. 81/2016, p. 233 - 266, Jan - Mar / 2016.

FERREIRA, HelineSivini. A repartição de competências em matéria ambiental. In: Manual de Direito Ambiental. LEITE, José Rubens Morato (coord.). São Paulo: Saraiva, 2015.

FIGUEIREDO, Lúcia Valle. Discriminação constitucional da competências ambientais: aspectos pontuais do regime jurídico das licenças ambientais. In: Direito Ambiental: fundamentos do direito ambiental. MILARÉ, Édis; MACHADO, Paulo Affonso Leme (orgs.). Coleção doutrinas essenciais, v. 1. São Paulo: Editora Revista dos Tribunais, 2011. 
FRANCO, Ana Cláudia La Plata de Mello; GIACOMOLLI, Gabriela Silveira. Do regime de proteção às Áreas de Preservação Permanente. In: Novo código florestal: comentários à Lei 12.651, de 25 de maio de 2012, à Lei 12.727, de 17 de outubro de 2012 e do Decreto 7.830, de 17 de outubro de 2012. MILARÉ, Édis; MACHADO, Paulo Affonso Leme (Coord.). $2^{\text {a }}$ ed. rev., atual. e ampl. São Paulo: Editora Revista dos Tribunais, 2013.

GUERRA, Sidney; GUERRA, Sérgio. Intervenção estatal ambiental: licenciamento e compensação de acordo com a Lei complementar $\mathrm{n}^{\circ}$ 140/2011. São Paulo: Atlas, 2012.

LEITE, José Rubens Morato (Coord.). Manual de Direito Ambiental. São Paulo: Saraiva, 2015.

LEITE, José Rubens Morato; AYALA, Patryck de Araújo. Dano ambiental: do individual ao coletivo extrapatrimonial: teoria e prática. 7 . ed. rev., atual., e ampl. São Paulo: Editora Revista dos Tribunais, 2015.

LEITE, José Rubens Morato; MELO, Melissa Ely. Reparação do dano ambiental: considerações teóricas e normativas acerca de suas novas perspectivas e evolução. In: Congresso Brasileiro do Magistério Superior de Direito Ambiental da Arodab. 8., Rio de Janeiro, 2008. Disponível em: <http://www.nima.puc-rio.br/aprodab/melissa_ely_mello_e_jose_ rubens_morato_leite.pdf $>$. Acesso em: 20 fev. 2017.

LEITE, José Rubens Morato; PILATI, Luciana Cardoso. Reparabilidade do dano ambiental no sistema da responsabilização civil: 25 anos da lei 6938/1981. Revista Sequência, no 53, p. 43-80, dez. 2006.

LOTT, Vinicius Freitas. Compensação ambiental: instrumento econômico para a tutela do meio ambiente. In: Congresso Nacional do CONPEDI, 18. 2009, São Paulo. Anais...São Paulo, 2009. Disponível em: <http://www. publicadireito.com.br/conpedi/manaus/arquivos/anais/sao_paulo/2726. pdf $>$. Acesso em: novembro de 2016.

MACHADO, Paulo Affonso Leme. Direito Ambiental Brasileiro. 21 $1^{\mathrm{a}} \mathrm{ed}$. rev., atual. e ampl. São Paulo: Malheiros Editores, 2013.

MACHADO, Paulo Affonso Leme. Direito Ambiental Brasileiro. $22^{\mathrm{a}}$ ed. rev., ampl. e atual. São Paulo: Malheiros Editores, 2014.

MACIEL, Marcela Albuquerque. Compensação ambiental: instrumento para implementação do Sistema Nacional de Unidades de Conservação. Dissertação (Mestrado em Direito). Centro Universitário de Brasília, 2012. 
MELO, Ana Alice Moreira de. Compensação Ambiental na Lei do Sistema Nacional de Unidades de Conservação. São Paulo: Nelpa, 2011.

MILARÉ, Édis. Direito do Ambiente. 8. ed. rev. atual. São Paulo: Revista dos Tribunais, 2013.

MILARÉ, Édis. Direito do Ambiente. $9^{a}$ ed. rev., atual. e ampl. São Paulo: Editora Revista dos Tribunais, 2014.

MILARÉ, Édis; ARTIGAS, Priscila Santos. Compensação ambiental: questões controvertidas. Revista de Direito Ambiental, vol. 43, p. 101 114, Jul - Set / 2006.

MILARÉ, Lucas Tamer. O licenciamento ambiental: Contribuições para um marco legislativo à luz do pacto federativo ecológico instituído pela Lei Complementar 140/2011. Tese (Doutorado em Direito das Relações Sociais) - Pontifícia Universidade Católica de São Paulo, 2016.

MIRRA, Alvaro Luiz Valery. Participação, processo civil e defesa do meio ambiente no direito brasileiro. 2010. Tese (Doutorado em Direito Processual) - Faculdade de Direito, Universidade de São Paulo, São Paulo, 2010.

MOTA, Mauricio. A Função socioambiental da propriedade: a compensação ambiental como decorrência do princípio do usuário pagador. Revista de Direito da Cidade, Rio de Janeiro, vol.07, nº 02, pp.776-803, 2015.

MOTTA, Diana Meirelles da; PÊGO, Bolívar (orgs.). Licenciamento ambiental para o desenvolvimento urbano: avaliação de instrumentos e procedimentos. Rio de Janeiro: Ipea, 2013.

MOTTA, Ronaldo Seroa da. Manual para valoração econômica de recursos ambientais. Rio de Janeiro: IPEA/MMA/PNUD/CNPq, 1997.

MUKAI, Toshio. Legislação, meio ambiente e autonomia municipal. Doutrinas essenciais de direito constitucional. vol. 3, p. 1249 - 1260, maio 2011.

NASCIMENTO, Sílvia Helena Nogueira. Competência para o licenciamento ambiental na Lei Complementar $n^{\circ}$ 140/2011. São Paulo: Atlas, 2015.

OGAWA, William Afonso. Compensação ambiental e unidades de conservação: questões sensíveis e visões econômica e jurídica. Dissertação 
(Mestrado em Economia - Gestão Econômica do Meio Ambiente). Universidade de Brasília, 2010.

OLIVEIRA, Cláudia Alves de. Competências ambientais na federação brasileira. Revista de Direito da Cidade, Rio de Janeiro, vol. 04, n. 02, p. 40-64, 2012.

RODRIGUES, Marcelo Abelha. Aspectos jurídicos da compensação ambiental do art. $36, \S 1 .^{\circ}$ da lei brasileira das unidades de conservação (Lei 9.985/2000). Revista de Direito Ambiental. vol. 46, p. 130 - 145. abr - jun / 2007.

SILVEIRA, Vladimir Oliveira da. O princípio da autonomia municipal e os assuntos de interesse local na Constituição Federal de 1988. Revista Tributária e de Finanças Públicas. vol. 61, p. 212 - 227, mar - abr / 2005.

SOARES, Sinara. As inovações da base de cálculo da compensação ambiental da lei do Sistema Nacional de Unidades de Conservação - Dec. 6.848/2009. Revista de Direito Ambiental. vol. 69, p. 299-313, jan - mar / 2013.

Recebido em: 20/02/2018. Artigo aceito em: 09/05/2018.

\section{Como citar este artigo (ABNT):}

SOUSA, Ricardo Azevedo Mamédio de; ROCHA, Renata Rodrigues de Castro. ATUAÇÃO MUNICIPAL NA MITIGAÇÃO DE IMPACTOS AMBIENTAIS. Veredas do Direito, Belo Horizonte, v. 15, n. 31, p. 293 323, jan./abr. 2018. Disponível em: <http://www.domhelder.edu.br/revista/ index.php/veredas/article/view/1249>. Acesso em: dia mês. ano. 